\title{
ALGUNAS REFLEXIONES SOBRE COPIA, PLAGIO Y FRAUDE EN LA EVALUACIÓN UNIVERSITARIA
}

\author{
Prof. Dr. F. Manuel Montalbán Peregrín \\ Defensor de la Universidad de Málaga
}

El pasado 5 de mayo de 2014 celebramos una jornada de estudio y debate, organizada por la Oficina del Defensor Universitario de la Universidad de Málaga, centrada en la copia, el plagio y el fraude en los procesos de evaluación. Posteriormente se desarrolló el 22 de octubre de 2014 una mesa de trabajo sobre copia, fraude intelectual, derechos de autor y propiedad intelectual, en el marco del XVII Encuentro Estatal de Defensores Universitarios, en el campus de Badajoz de la Universidad de Extremadura. Esta aportación refleja algunas reflexiones y conclusiones derivadas de estos encuentros.

\section{Contexto}

Los actuales sistemas de enseñanza-aprendizaje exigen a nuestros estudiantes mayores esfuerzos de autonomía, trabajo continuado, creatividad, participación, etc. Los avances de las nuevas tecnologías conllevan efectos diversos, pero también paradójicos, para los procesos académicos implicados. La facilidad de acceso a una información globalizada representa en muchas ocasiones un verdadero aluvión de contenidos necesitado del establecimiento de criterios claros de calidad y prioridad. Una cantidad casi infinita de informaciones está disponible para ser re-apropiada con un simple comando.

La comunidad educativa universitaria está preocupada también por las formas de presentación de un viejo problema: la copia en los exámenes. Problema revitalizado por el uso de las nuevas tecnologías que convierten los dispositivos de fraude más avanzados en indetectables para los viejos usos y costumbres de vigilancia de exámenes. Este tipo de prácticas afectan además a la vida académica introduciendo dimensiones de inequidad para aquellos estudiantes cuyo resultado sí es fruto de su esfuerzo y dedicación personal al estudio.

Asimismo aumentan también las solicitudes de información y orientación a las Defensorías Universitarias sobre conflictos de autoría en la elaboración de trabajos, proyectos, estudios, artículos, etc., tanto por parte de los docentes cuanto de los propios estudiantes, no 
solo de master y doctorado, cada día más implicados en la redacción de textos que aspiran a poder ser difundidos entre la comunidad científica.

\section{Naturaleza multidimensional}

El hecho de analizar con rigor estas realidades y elaborar medidas de actuación eficaces implica definir la cuestión en su naturaleza poliédrica, promoviendo el compromiso conjunto de órganos académicos, estudiantes y profesores, desde una perspectiva integral y constructiva, que vaya más allá de una política meramente coercitiva-disciplinaria. Sureda, Comas y Morey (2009)1ㄹ , en un interesante trabajo sobre el plagio académico, informan de que los propios docentes universitarios señalan la comodidad, las facilidades que ofrece Internet, cierto sentimiento de impunidad y la inhabilidad para realizar trabajos académicos como las causas más importantes asociadas al plagio entre el alumnado. Asimismo los docentes relacionan este tipo de prácticas con su propio comportamiento como docentes y con la metodología y estrategias didácticas empleadas.

Se trata de una amalgama de viejas y nuevas prácticas entre las que, con fines aclaratorios, podemos distinguir las categorías:

- Recurso a fuentes de información no permitidas durante los actos de evaluación.

- Uso fraudulento de nuevas tecnologías para acceder a información o material relevante.

- Uso indebido de material textual disponible, desde arrogarse autoría hasta abuso del “copy \& paste”, citación incorrecta o inexistente, etc.

- No reconocimiento de colaboración, tutorización, coautoría, en trabajos académicamente dirigidos, de iniciación a la investigación, proyectos, etc.

Las propias causas de este tipo de acciones hay que buscarlas tanto en factores externos a la propia Universidad, que sobrepasan la vida académica pero la impregnan también de manera inevitable, de carácter cultural, ético, desarrollo tecnológico, etc., cuanto en factores intrínsecos al Sistema de Educación Superior. Comas y Sureda $(2008)^{2}$, por su parte, resaltan una serie de factores intrasistema, entre los que destacamos:

\footnotetext{
1 Sureda, J., Comas, R. y Morey, M. (2009), "Las causas del plagio académico entre el alumnado universitario según el profesorado”. Revista Iberoamericana de Educación 50, 197-220.

2 Comas, R. y Sureda, J. (2008), "El ciberplagi acadèmic: esbrinant-ne les causes per tal d'enllestir les solucions". Digithum, 10, 1-6.
} 
- Masificación en las aulas, que ha desbordado la cultura del pequeño grupo inspirador de ciertas metodologías ECTS.

- Escaso desarrollo de competencias documentales en los nuevos planes de estudio.

- Demandas de trabajo que "incitan” al plagio: reiteración año a año de la demanda académica, poco control, evaluación superficial, escasa retroalimentación, más interés en lo informacional, énfasis en el resultado vs. proceso, etc.

- Demandas de trabajos excesiva, poco conectada a la recomendación de número de horas de trabajo del estudiante en el cómputo de los créditos ECTS.

- Deficiente gestión del tiempo y recursos por parte de los estudiantes.

- Paulatina extensión del cambio de visión del estudiante como mero consumidor de servicios.

- Competitividad entre los estudiantes.

- Economía de esfuerzo, comodidad, facilidad, anonimato de las TIC's.

- Desconexión con la normativa académica, desconocimiento, tendencia al plagio no intencional.

- Insuficiente coordinación de los equipos docentes.

\section{Necesidad de respuestas innovadoras}

La construcción mediática que del fenómeno se está difundiendo refleja una imagen pública de la Universidad de ineficacia e inequidad, sobre todo si se prima la tensión existente entre educación superior y sistema disciplinario, con un marco jurídico general obsoleto y necesitado de una revisión urgente, y una amplia variedad reglamentaria propia de las universidades. Frente a intentos más elaborados, muchas de estas propuestas reglamentarias se contentan con articulados de orden general, sin concretar definiciones ni consecuencias específicas, haciendo recaer el peso de las consecuencias concretas en la relativa autonomía y savoir-faire de los equipos docentes. En general, el tema que nos ocupa se presenta desde una perspectiva unilateral centrada en la evitación, poner impedimentos, ejercer mayor control, y concretar sanciones. Pero si valoramos el carácter multidimensional de este tipo de prácticas debemos confrontarnos con la necesidad de articular respuestas conectadas a la corresponsabilidad y la naturaleza de los cambios de metodología docente que estamos introduciendo. Asimismo no es recomendable olvidar el difícil equilibrio entre derechos y deberes en juego en procedimientos que implican acusaciones de copia, plagio o fraude. 
Por todo ello, incluimos para la discusión los siguientes elementos a tener presentes en nuestra labor de enfrentamiento de estas prácticas.

- Necesidad de definir las situaciones de copia, plagio y fraude en los procesos de evaluación en la Universidad desde una perspectiva multidimensional, que contemple aspectos académicos, pedagógicos, administrativos, sociales, etc.

- Necesidad de articular respuestas conectadas a los cambios culturales para la organización universitaria y las metodologías docentes introducidos por el Espacio Europeo de Educación Superior.

- Oportunidad de incorporar en los procesos de matriculación compromisos éticos por parte de los estudiantes, en forma de declaraciones de integridad académica.

- Clarificación de prácticas y comportamientos no permitidos y sus consecuencias en la calificación de las materias.

- Mayor detalle de sanciones administrativas derivadas del incumplimiento de estos compromisos académicos. En este punto es de especial relevancia la conveniencia de distinguir, y ajustar a nuestro marco normativo, la diferencia entre el componente administrativo y disciplinario de estas sanciones.

- Definición de procedimientos sencillos de constatación, con la implicación del Departamento y las Comisiones de Ordenación Académica, de que la práctica fraudulenta se ha producido.

- Apuesta por una evaluación aplicada, que realce la creatividad del estudiante y valore las competencias necesarias en contextos diversos, donde la literalidad de los materiales y contenidos estudiados no sea el ingrediente determinante.

- Posibilidad de utilización de otras dimensiones de evaluación, complementarias a las pruebas escritas, por ejemplo, preparación y presentación de bibliografía comentada, informes, estudios, póster, etc., donde los componentes escritos de la evaluación tengan oportunidad de ser defendidos oralmente.

- Desarrollo de competencias documentales y de gestión de la información por parte de nuestros estudiantes, conjuntamente con la extensión de una cultura dentro del aula de respeto a la autoría intelectual y ética de la "intertextualidad”.

- Conocimiento previo y claridad de las condiciones de admisión a las pruebas de evaluación (p.e. prohibición de portar dispositivos electrónicos, materiales de clase, etc., en el puesto asignado). 
- Mayor coordinación de los equipos docentes (p.e. fechas de entrega de trabajos entre los distintos grupos de docencia).

- Presencia activa de docentes en la supervisión de las pruebas.

- Definición clara de la labor y responsabilidad académica del tutor en los TFM y TFG.

- Utilización de herramientas, como el Ephorus, para detectar situaciones de plagio académico, analizando porcentajes de coincidencia con otros trabajos o publicaciones. 